\title{
Mesenchymal stem cells derived from human placenta suppress allogeneic umbilical cord blood lymphocyte proliferation
}

\author{
Chang Dong $\mathrm{LI}^{1}$, Wei Yuan ZHANG ${ }^{1, *}$, He Lian $\mathrm{LI}^{2}$, XiaoXia JIANG ${ }^{3}$, Yi ZHANG ${ }^{3}$, Peihsien $\mathrm{TANG}^{3}$, Ning MAO \\ ${ }^{1}$ Beijing Gynecology and Obstetrics hospital, Affiliate of Capital University of Medical Sciences, Beijing 100026, China \\ ${ }^{2}$ Department of Gynecology and Obstetrics, Second Hospital of Jilin University, Changchun 130021, China \\ ${ }^{3}$ Department of Cell Biology, Institute of Basic Medical Sciences, Academy of Military Medical Sciences, Beijing 100850, \\ China
}

\begin{abstract}
Human placenta-derived mononuclear cells (MNC) were isolated by a Percoll density gradient and cultured in mesenchymal stem cell (MSC) maintenance medium. The homogenous layer of adherent cells exhibited a typical fibroblastlike morphology, a large expansive potential, and cell cycle characteristics including a subset of quiescent cells. In vitro differentiation assays showed the tripotential differentiation capacity of these cells toward adipogenic, osteogenic and chondrogenic lineages. Flow cytometry analyses and immunocytochemistry stain showed that placental MSC was a homogeneous cell population devoid of hematopoietic cells, which uniformly expressed CD29, CD44, CD73, CD105, CD166, laminin, fibronectin and vimentin while being negative for expression of CD31, CD34, CD45 and $\alpha$-smooth muscle actin. Most importantly, immuno-phenotypic analyses demonstrated that these cells expressed class I major histocompatibility complex (MHC-I), but they did not express MHC-II molecules. Additionally these cells could suppress umbilical cord blood (UCB) lymphocytes proliferation induced by cellular or nonspecific mitogenic stimuli. This strongly implies that they may have potential application in allograft transplantation. Since placenta and UCB are homogeneous, the MSC derived from human placenta can be transplanted combined with hematopoietic stem cells (HSC) from UCB to reduce the potential graft -versus-host disease (GVHD) in recipients.
\end{abstract}

Keywords: mesenchymal stem cells, human placenta, umbilical cord blood, immune regulation.

\section{INTRODUCTION}

Human mesenchymal stem cells (MSC), which are first isolated from bone marrow (BM) $[1,2]$ and subsequently isolated from other tissues such as adipose tissue, cutaneous tissue, fetal hepatic and pulmonary tissue [3-11], are pluripotent progenitors for a variety of tissues including bone, cartilage, tendon, fat, and muscle [12]. It has been approved have the capability to support expansion of hematopoietic stem cells (HSC) through expressing cytokines and reconstructing hematopoietic microenvironment $[13,14]$. Furthermore, preliminary investigation has revealed that MSC are not immunogenic although weekly expressing class II major histocompatibility complex (MHC-II) $[15,16]$. MSC also exhibit immuno-

\footnotetext{
*Correspondence: Wei Yuan ZHANG

Tel: +86-10-85976699-8082; Fax: +86-10-85968396;

E-mail: zhangwy9921@hotmail.com
}

regulatory properties, which have a direct immunosuppressive effect on T cell proliferation in vitro, as demonstrated by their ability to suppress the mixed lymphocyte reaction (MLR) $[17,18]$. So the MSC are co-transplanted with HSC in order for improving hematopoietic engraftment rate and pace, and ameliorating or preventing graft-versus-host disease (GVHD).

Currently, BM represents the main source of MSC for both experimental and clinical studies. The use of BM derived cells is not always acceptable due to the high degree of viral infection and the significant drop in cell number and proliferate/differentiation capacity with age. Thus, the search for possible alternative MSC sources remains to be necessary. Placenta is composed of vessel, mesenchyma and trophocyte. The genesis of MSC is thought to be mesoderm while the genesis of placenta is extraembryonic mesoderm. In essence, mesoderm and extraembryomic mesoderm are homological. So placenta is considered a new source of MSC [19]. 
Allogeneic transplantation with umbilical cord blood (UCB) in adult recipients is limited mainly by a low CD34 ${ }^{+}$ cell dose and the following GVHD. Placenta and UCB are homogeneous (both are fetal appertaining and extraembryonic mesoderm original), and the adherent cells from placenta as feeder is much better than the stromal cells from BM for UCB expanded in vitro [20]. Our study aimed at isolating and characterizing MSC in human placenta, which would possibly open a new and rich source of MSC for experimental and clinical needs, especial for the transplantation of UCB HSC.

\section{MATERIALS AND METHODS}

\section{Isolation and culture of human placental MSC}

UCB and fetal placentas $(n=24)$ were collected from normal fullterm pregnancies according to the regulations of the Research Ethics Committee of Beijing Gynecology and Obstetrics Hospital. Loose chorion, amniotic sac, and decidua were removed from the placenta immediately after collection. The placentas were washed extensively with phosphate-buffered saline (PBS) and flushed with perfusate and Iscove's modified Dulbecco medium (IMDM; GIBCO Invitrogen Corp, Paisley, UK, Scotland) supplemented with heparin 12.5 U/ $\mathrm{ml}$, penicillin $50 \mathrm{U} / \mathrm{ml}$, and streptomycin $50 \mathrm{mg} / \mathrm{ml}$ through the arterial-vein circuit to eliminate tissue residual blood. The placenta was soaked with 200 to $250 \mathrm{ml}$ of medium for 12 to $24 \mathrm{~h}$ at $20^{\circ} \mathrm{C}$ to $25^{\circ} \mathrm{C}$. The mononuclear cells (MNC) in the medium were recovered by Percoll density gradient fractionation $(<1.073 \mathrm{~g} / \mathrm{ml}$, Pharmacia, Piscataway, NJ, USA), washed, and resuspended in Dulbecco's modified Eagle medium-low glucose (DMEM-LG; GIBCO) supplemented with 10\% fetal bovine serum (FBS; Lot\# 2B203998, Stem Cell Technologies, Vancouver, BC, Canada). After $10 \mathrm{~d}$ of culture with $5 \% \mathrm{CO}_{2}$ at $37^{\circ} \mathrm{C}$, individual colonies were isolated and expanded. When the cultures reached approximately $90 \%$ monolayer confluence, cells were recovered by using $0.25 \%$ trypsin- 1 mM EDTA (Sigma Chemical Co, St. Louis, MO, USA) for culture expansion and further identification.

\section{Characterization of culture-expanded human placental MSC}

Placental adherent cells were phenotypically characterized by flow cytometry (Becton-Dickinson, San Jose, CA, USA). Fluorescein isothiocyanate (FITC)-conjugated or phycoerythrin (PE) -conjugated antibodies against CD29, CD31, CD34, CD44, HLA-ABC, HLA-DR, CD73, CD166 (PharMingen, San Diego, CA, USA); CD45 (Becton-Dickinson); and CD105 (SEROTEC, Oxford, UK) were used. To detect surface antigens, cells were detached with $0.25 \%$ trypsin -1mM EDTA in PBS, washed with PBS containing $2 \%$ bovine serum albumin (BSA; Sigma) and $0.1 \%$ sodium azide (Sigma), and incubated $\left(30 \mathrm{~min}\right.$ at $\left.4^{\circ} \mathrm{C}\right)$ with the respective antibody at a concentration previously established by titration. In each case, $1 \times 10^{4}$ cells were acquired and analyzed by using the Cell Quest software (Becton-Dickinson).

Moreover, human placental adherent cells were analyzed by immunocytochemistry. Cells were fixed in equal volumes of methanol and acetone for $1 \mathrm{~min}$ at room temperature, washed with PBS, incubated with $3 \%$ hydrogen peroxide $\left(\mathrm{H}_{2} \mathrm{O}_{2}\right.$; Sigma-Aldrich, St. Louis, MO, USA), and blocked with $10 \%$ normal goat serum at room temperature. Washed cells were incubated with the following primary antibodies: rabbit anti-human laminin polyclonal antibody (Dako, Gostrup, Denmark), mouse anti- $\alpha$-smooth muscle actin mAb (Sigma-Aldrich), rabbit anti-human fibronectin polyclonal antibody (Sigma-Aldrich), and mouse anti-vimentin McAb (Sigma-Aldrich) at 1:100 dilutions with antibody diluents (Dako) for $30 \mathrm{~min}$ at room temperature. Anti-mouse or anti-rabbit peroxidase-conjugated immunoglobulin G antibody (Santa Cruz, CA, USA) was used as a secondary antibody at 1:100 dilution, and 3,3'-diaminobenzidine in chromogen solution (Dako) was applied to the slides, which were counterstained with $0.1 \%$ Mayer hematoxylin solution (SigmaAldrich).

\section{Differentiation assay of human placental MSC}

Osteogenic differentiation was assessed by incubating the cells with DMEM-high glucose (HG) plus 10\% FBS supplemented with $10^{-4} \mathrm{mM}$ dexamethasone, $0.5 \mathrm{mM}$ ascorbic acid, and $10 \mathrm{mM} \beta$-glycerol phosphate (Sigma) for 2 to $4 \mathrm{w}$. Osteoblasts were identified by immunocytochemical stain with alkaline phosphatase (ALP). To assess mineralization, deposit calcium in cultures was stained with silver nitrate (Sigma) by the method of von Kossa [21].

To study adipogenic differentiation potential, cells were cultured as monolayers, allowed to become near confluent, and then incubated with DMEM-HG plus $10 \%$ FBS supplemented with $10^{-3} \mathrm{mM}$ dexamethasone, $0.5 \mathrm{mM}$ isobutyl methylxanthine, $0.2 \mathrm{mM}$ indomethacin, and $10 \mu \mathrm{g} / \mathrm{ml}$ insulin (Sigma) for $2 \mathrm{w}$. To demonstrate the presence of adipocytes, cytoplasmic inclusions of neutral lipids were stained with oil-red-O (Sigma) [22].

Medium with DMEM containing 2.5\% FBS, $50 \mathrm{ng} / \mathrm{ml}$ transforming growth factor-b1 (Peprotech, London, UK), $50 \mu \mathrm{g} / \mathrm{ml}$ ascorbic acid, $1 \mathrm{mM}$ sodium pyruvate, $6.25 \mu \mathrm{g} / \mathrm{ml}$ bovine insulin, $6.25 \mu \mathrm{g} / \mathrm{ml}$ transferrin, $6.25 \mu \mathrm{g} / \mathrm{ml}$ selenious acid, and $1.25 \mu \mathrm{g} / \mathrm{ml} \mathrm{BSA}$ was used for chondrogenic differentiation. Chondrogenic differentiation was performed using the micromass culture technique as previously described [12]. Briefly cells were grown as a pelleted micromass. Under low-speed centrifugation, a dense mass of cells formed at the bottom of the conical centrifuge tube and the cultures were maintained in the chondrogenic medium for $2 \mathrm{w}$. Alcian blue staining was used to assess the formation of extracellular matrix, which is the mark of chondrogenic differentiation.

\section{Reverse transcription-polymerase chain reaction (RT-PCR)}

To further test differentiation of placental MSC in vitro assays, RNA from cells after differentiation was isolated and RT-PCR was used to amplify expressed transcripts from multiple genes whose expression is restricted to the adipocytic (paroxysm proliferation activated receptor gamma 2, PPAR $\gamma 2$ ), osteocytic (osteopontin, OP) and chondrocytic (type II collagen, collagen II) lineage [12].

Total RNA was extracted from cultures of the MSC with TRIzol reagent (Gibco Laboratories, Carlsbad, CA, USA), following the manufacturer's instructions. Briefly, removed $2 \times 10^{6}$ harvested cells to a $1.5 \mathrm{ml}$ centrifugal tube and added $1 \mathrm{ml}$ TRIzol reagent. Chloroform and isopropanol were used to extract RNA from lysate. RNA was washed in $1 \mathrm{ml} 75 \%$ ethanol and dissolved in diethyl pyrocarbonate (DEPC) treated water. RNA was converted to cDNA using oligo-dT primer and AMV reverse transcriptase (Takara, Kyoto, Japan). PCR cycles were optimized for each set of primers (Tab. 1). As the same amount cDNA templates were used to all reactions, in comparison to the $\beta 2$ microglobulin standard, the expression levels were evaluated. The PCR products were analyzed by electrophoresis on $2 \%$ agarose gel containing $1 \mu \mathrm{g} / \mathrm{ml}$ ethidium bromide. 
Tab. 1 Oligonucleotide primers used for the PCR detection of gene transcripts

\begin{tabular}{|c|c|}
\hline Primers & Size (bp) \\
\hline Human $\beta 2$-Microglobulin & 335 \\
\hline \multicolumn{2}{|c|}{ Upper: 5' CTC GCG CTA CTC TCT CTC TCT TTC TGG 3' } \\
\hline \multicolumn{2}{|l|}{ Lower: 5' GCT TAC ATG TCT CGA TCC CAC TTAA 3' } \\
\hline Human PPAR- $\gamma 2$ & 174 \\
\hline \multicolumn{2}{|l|}{ Upper: 5'TGTCAGTACTGTCGGTTTC 3' } \\
\hline \multicolumn{2}{|l|}{ Lower: 5'AATGGTGATTTGTCTGTTG 3' } \\
\hline Human osteopontin & 241 \\
\hline \multicolumn{2}{|l|}{ Upper: 5'GTGCCATACCAGTTAAACA 3' } \\
\hline \multicolumn{2}{|l|}{ Lower: 5'CTTACTTGGAAGGGTCTCT 3' } \\
\hline Human collagen II & 394 \\
\hline \multicolumn{2}{|l|}{ Upper: 5'AGTGGAGACTACTGGATTGA 3' } \\
\hline Lower: 5'AGTGTACGTGAACCTGCTAT 3' & \\
\hline
\end{tabular}

\section{Isolation and culture of UCB lymphocytes and adult periph- eral blood (PB) lymphocytes}

UCB were collected according to institutional guidelines after the informed consent was obtained from mother. MNC were isolated prior to processing from the cord blood using Ficoll-Hypaque (lymphoprep, $1.077 \pm 0.001 \mathrm{~g} / \mathrm{ml}$, Pharmacia) density gradient centrifugation. $\mathrm{CD} 34^{+}$cells were purified by utilized positive selection using the direct miniMACS magnetic cell sorting system (Miltenyi Biotec, Germany) according to the manufacturer's instructions and CD34 cells were collected. Briefly, UCB MNC were incubated for 30 min at $4^{\circ} \mathrm{C}$ with human IgG to block the Fc receptors and monoclonal CD34 antibodies directly conjugated with MicroBeads. After being labeled, the cell suspension was passed though a column held within a magnetic field causing $\mathrm{CD} 34^{+}$cells to be retained in the column and unlabeled CD34 cells to be wash out. CD34 cells were collected.

PB were collected from healthy adult after the informed consent was obtained. Then MNC were isolated from the heparinized blood by using Ficoll-Hypaque (Lymphoprep, $1.077 \pm 0.001 \mathrm{~g} / \mathrm{ml}$ ) density gradient centrifugation and collected from the interface.

The isolated MNC from adult $\mathrm{PB}$ and the $\mathrm{CD} 34^{-}$cells from $\mathrm{UCB}$ were cultured at RPMI 1640 medium (GIBCO BRL) supplemented with $20 \%$ FBS for $24 \mathrm{~h}$ to remove monocytes by adherence then the remained UCB lymphocytes and PB lymphocytes were collected and counted for later study.

\section{Lymphocyte transformation test (LTT) and MLR}

The MSC from human placenta were irradiated (15 Gy) and plated $24 \mathrm{~h}$ ahead co-cultured with lymphocytes. Cell counts and viability were assessed by trypan blue dye exclusion. Responding CB lymphocytes $\left(2 \times 10^{5} /\right.$ well $)$ were cultured in triplicate mixed at different ratios with MSC in flat bottom 96-well plates to ensure efficient cell-cell contact for $4 \mathrm{~d}$ in $0.2 \mathrm{ml}$ RPMI 1640 medium (GIBCO BRL) containing $20 \%$ heat-inactivated FBS. In mitogen proliferative assays, LTT, responding cells were stimulated by nonspecific mitogenic stimuli, phytohemagglutinin (PHA; Sigma), $2 \mu \mathrm{g} / \mathrm{ml}$. And in MLR, an equal number of irradiated ( $30 \mathrm{~Gy})$ PB lymphocytes $\left(2 \times 10^{5}\right.$ per well) were stimulating cells. All the plates were pulsed with $1 \mu \mathrm{Ci}$ / well ${ }^{3} \mathrm{H}$-thymidine during the last $12 \mathrm{~h}$ of a four-day culture. Lymphocytes proliferation was evaluated by measuring ${ }^{3} \mathrm{H}-\mathrm{TdR}$ using a liquid scintillation counter. Cells were harvested over fiberglass filters and thymidine uptake quantified with a Microbeta scintillation counter (Beckman). The experiments were repeated at least three times.

\section{Statistics}

Results are expressed as mean $\pm \mathrm{SD}$, and statistical comparisons were performed using the two-sided Student $t$ test. $p$ values less than 0.05 were considered statistically significant.

\section{RESULTS}

\section{Adherent, fibroblast-like cells from human placenta}

A density gradient was used in the isolation procedure to eliminate unwanted cell types that were present in the placenta perfusate. While plated at a low density $(12,000 /$ $\mathrm{cm}^{2}$ ), a small percentage isolated from the density interface of $1.073 \mathrm{~g} / \mathrm{ml}$, cells were scattering attached (Fig. 1A) and grew as fibroblastic cells that developed into visible symmetric colonies at about 5 to $7 \mathrm{~d}$ after initial plating (Fig. 1B). Nonadherent cells were removed with changes in medium at 24 to $48 \mathrm{~h}$. In all of the 24 placental samples, various numbers of colonies were harvested. But not all the colonies could form an adherent layer and remain as fibroblast-like cells (Fig. 1C). In each placenta, the numbers of the colonies which could be readily expanded in vitro by successive cycles of trypsinization, seeding, and culture every $3 \mathrm{~d}$ for 15 passages without visible morphologic alteration were listed in Tab. 2. Six randomly selected colonies in different placenta were used for later experiments.
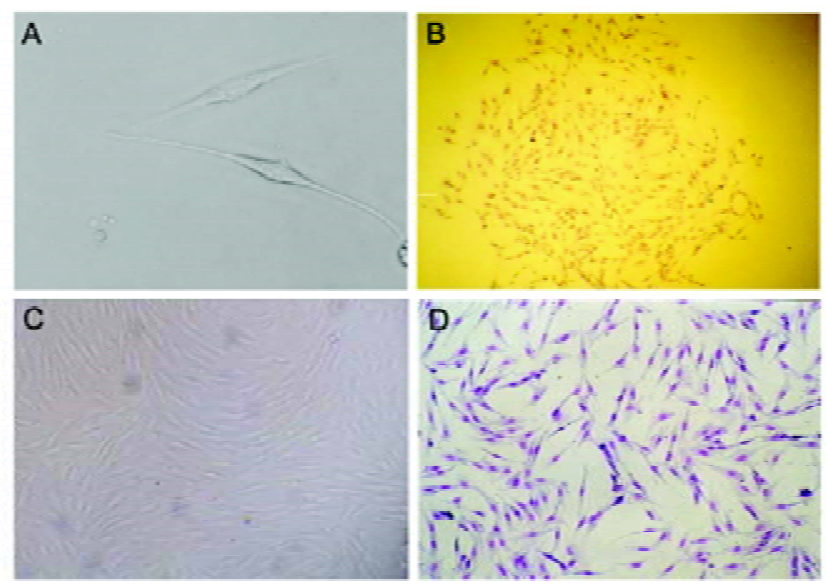

Fig. 1 Characterization of isolated placental adherent cells. Cells were cultured from placenta after density fractionation and are shown at $72 \mathrm{~h}$ after plating (A) and at $10 \mathrm{~d}$ after plating (B). Morphology of passage 3 cultures of MSC from placenta (C,D). 
Tab. 2 Numbers of the colonies in each placenta

\begin{tabular}{cccccccccccccc}
\hline $\mathbf{P}$ & $\mathrm{P} 1$ & $\mathrm{P}^{*}$ & $\mathrm{P}^{*}$ & $\mathrm{P} 4$ & $\mathrm{P} 5$ & $\mathrm{P} 6$ & $\mathrm{P}^{*}$ & $\mathrm{P} 8$ & $\mathrm{P} 9$ & $\mathrm{P}^{*} 0^{*}$ & $\mathrm{P} 11$ & $\mathrm{P} 12$ \\
\hline $\mathbf{H}$ & 18 & 32 & 25 & 19 & 29 & 37 & 22 & 16 & 35 & 20 & 19 & 21 \\
$\mathbf{M}$ & 6 & 9 & 9 & 8 & 5 & 11 & 7 & 6 & 15 & 10 & 5 & 6 \\
\hline $\mathbf{P}$ & $\mathrm{P} 13$ & $\mathrm{P} 14^{*}$ & $\mathrm{P} 15$ & $\mathrm{P} 16$ & $\mathrm{P} 17$ & $\mathrm{P} 18$ & $\mathrm{P} 19$ & $\mathrm{P} 20^{*}$ & $\mathrm{P} 21$ & $\mathrm{P} 22$ & $\mathrm{P} 23$ & $\mathrm{P} 24$ \\
\hline $\mathbf{H}$ & 34 & 31 & 30 & 17 & 28 & 21 & 15 & 23 & 36 & 22 & 24 & 30 & 8 \\
$\mathbf{M}$ & 11 & 8 & 6 & 7 & 12 & 4 & 6 & 8 & 9 & 5 & 8 & 14 \\
\hline
\end{tabular}

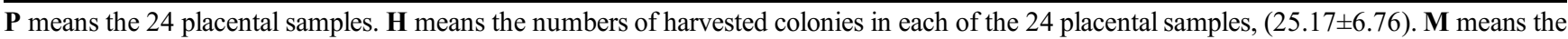
numbers of colonies which could be readily expanded in vitro by successive cycles of trypsinization, seeding, and culture every $3 \mathrm{~d}$ for 15 passages without visible morphologic alteration, and have immunophenotypic characterization of MSC, (8.13 \pm 2.88$)$.

"Six selected colonies in different placentas were used for later experiments.
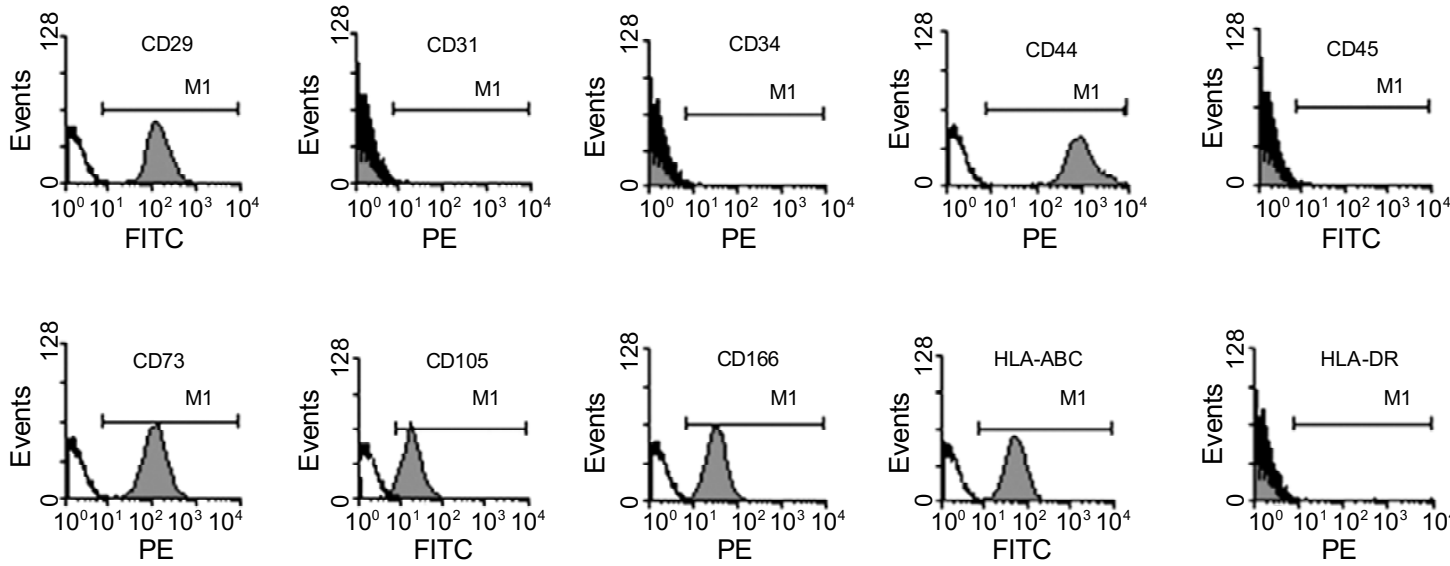

Fig. 2 Immunophenotyping of cultured MSC. Flow cytometric analysis of the status of mesenchymal, endothelial, and hemaotopoietic markers as well as adhesion-related antiogens in human placental derived MSC.

The growth kinetics and cell cycle of single colonyderived adherent cells were measured at passage 3 . The mean cumulative time of population doublings was 21 . $25 \pm 3.17 \mathrm{~h}$. Cell's DNA content was analyzed on a FACS Calibur with the Cell Quest software program (BectonDickinson) to analyze cellular cycle. Mostly cells of the MSC in placenta were at quiescent phase $\left(\mathrm{G}_{0} / \mathrm{G}_{1}\right.$ phase, $96.35 \pm 4.12 \%$ ), while very few cells at fissional phase, $\mathrm{G}_{2} / \mathrm{M}$ phase $(1.11 \pm 0.88 \%)$ and $\mathrm{S}$ phase $(2.54 \pm 1.03 \%)$.

\section{Immunophenotypic characterization of placental MSC}

MSC were analyzed for the expression of various antigens. Like the MSC from BM, these culture-expanded adherent cells were uniformly positive for CD29, CD44, CD73 (SH3, SH4) [23], CD105 (SH2) [24], CD166, HLA$\mathrm{ABC}$ (MHC-I molecule), laminin, fibronectin, and vimentin. In contrast, these cells were negative for other markers of the endothelial lineage $\mathrm{CD} 31$, the hematopoietic lineage CD34, the leukocyte common antigen CD45, and HLADR (MHC-II molecule), $\alpha$-smooth muscle actin (Fig. 2).
All isolated colonies derived MSC maintained a similar phenotype even at passage 15 . In addition, cryopreservation did not alter these immunophenotypic features.

\section{Differentiation the human placental MSC into osteocytes, adipocytes and chondrocytes}

The differentiation potential of MSC from placenta was tested by culturing cells under conditions that favored BM MSC differentiation into osteocytes, adipocytes and chondrocyte [25].

Differentiation of the cells into osteoblasts was induced in vitro by treating cells with low concentrations of dexa methasone, ascorbic acid, and $\beta$-glycerol phosphate. MSC cultured with osteoinductive medium underwent a dramatic change in cellular morphology from spindle-shaped to cuboidal, which was accompanied by an increase in ALP activity and hydroxyapatite mineral deposition.

Fig. 3A illustrates the ALP activity of subculture MSC grown in the presence of osteoblast inductive treatment after $2 \mathrm{w}$. A significantly greater ALP activity was observed 

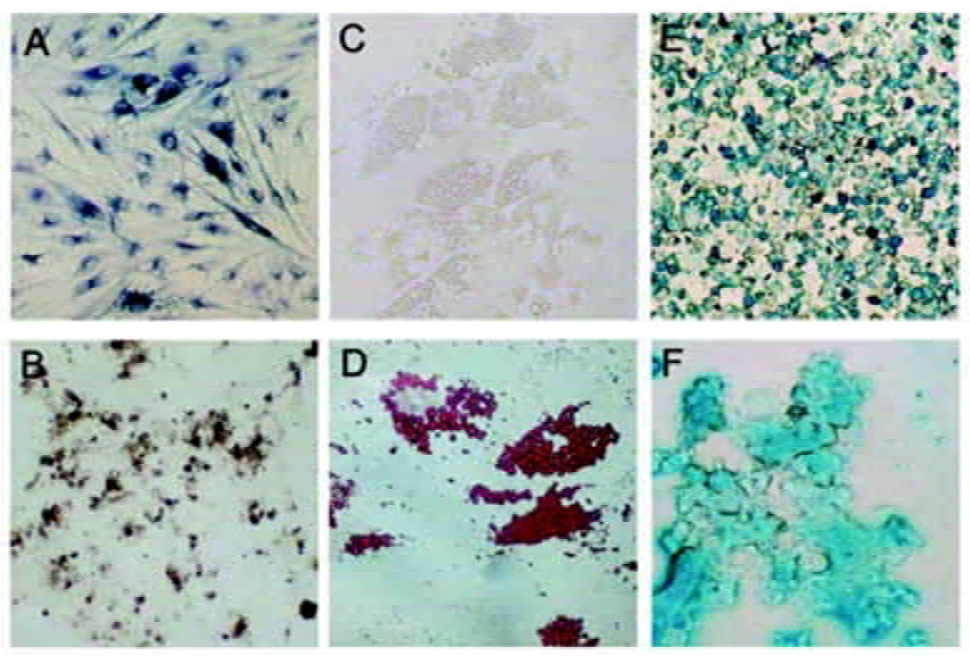

Fig. 3 in vitro differentiation of the MSC from human placenta. The accumulation of intracytoplasmic alkaline phosphatase (A) and calcium oxalates seen with Von Kossa staining (B) showed the differentiation of MSC into the osteoblast lineage. Adipogenesis was indicated by the presence of neutral lipid vacuoles that stain with oil-red-O $(\mathbf{C}, \mathbf{D})$. ECM was stained by Alcian blue $(\mathbf{E}, \mathbf{F})$ indicated the differentiation of MSC into the chondroblast lineage.

after $2 \mathrm{w}$ of osteoblast inductive treatment. These cultures were also studied for their ability to elaborate mineralized extra cellular matrix (ECM). As shown in Fig. 3B, MSC grown in osteoblast inductive medium showed a substantial calcium deposition on $\mathrm{w} 4$, while no calcium deposition was detected by von Kossa staining in control MSC cultures.

Adipogenic differentiation was induced in expanded MSC cultures by treatment with dexamethasone, insulin, indomethacin and hydroxybutylmethylxanthine. The differentiation was demonstrated by the accumulation of lipidrich vesicles. Accumulation of lipid-rich vesicles within cells appeared after incubated 3 to $5 \mathrm{~d}$ showed in Fig. 3C. Multiple induction treatments resulted in more than $95 \%$ of the cells committing to this lineage, and the lipid vacuoles continued to develop over time, coalesced, and eventually filled the cell. The lipid-rich vacuoles were diagnostic stained with Oil-red-O showed in Fig. 3D.

Chondrogenic differentiation can be induced in vitro using a micromass culture technique in which cellular condensation (a critical first event of chondrogenesis) is duplicated. Enhanced differentiation can be obtained by treating cells with dexamethasone and TGF- $\beta$. When cultured with these agents under micromass conditions, MSC formed cell nodules associated with a well-organized ECM rich in sulfated proteoglycans. These sulfated proteoglycans can be specifically detected using Alcian blue staining under acidic conditions. As shown in Fig. 3E and 3F, the MSC nodules cultured in chondrongenic-inductive medium were associated with an Alcian blue positive ECM, indicative of the presence of sulfated proteoglycans in undifferentiated MSC. This suggested that the MSC from human placenta possess the capacity to differentiate toward the chondrogenic lineage.

In agreement with the results of differentiation assays, RT-PCR also demonstrated that the adherent cells displayed corresponding transcriptional expression of PPAR $\gamma 2$, OP, and collagen II under specific adipogenic, osteogenic and chondrogenic inductive cultures, respectively. All these specific genes were assayed by RT-PCR after incubated 1 $\mathrm{w}$ with the differentiating medium, while the undifferentiated cultured cells expressed none of them (Fig. 4).

\section{MSC from human placenta suppress CB lymphocytes proliferation}

The immunosuppression effect of the MSC from human placenta on allogeneic adult PB lymphocytes was confirmed first, these cells could suppress PB lymphocytes proliferation stimulated by allogeneic PB lymphocytes and PHA like BM MSC (Fig. 5).

To test whether the MSC could inhibit a proliferative response by allogeneic $\mathrm{CB}$ lymphocytes, $\mathrm{CB}$ lymphocytes were cultured with allogeneic MSC at various doses. The effect of MSC on CB lymphocytes in the response was evaluated by mixing MSC and CB lymphocytes in the presence of various stimuli. There was a significant reduction in $\mathrm{CB}$ lymphocytes proliferation when mixed cultures of CB lymphocytes stimulated by irradiated allogeneic PB lym- 


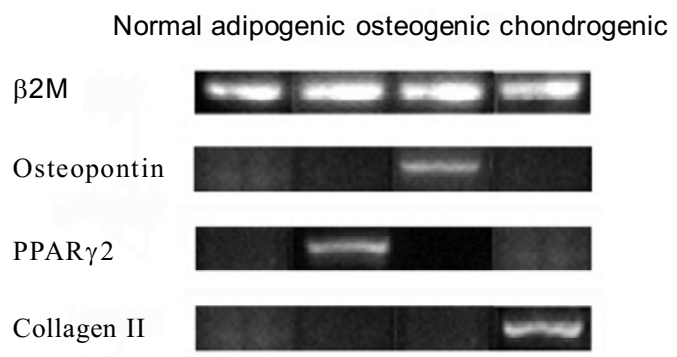

Fig. 4 Investigation of differentiation-specific genes expression. Cells cultured in control or inductive mediums for $1 \mathrm{w}$ were collected and analyzed for the expression of osteopontin, PPAR $\gamma 2$ and collagen II transcripts using RT-PCR.

phocytes (1:1 ratio) were performed in the presence of irradiated allogeneic MSC monolayer. Similarly, when CB lymphocytes proliferation was elicited by means of aspecific polyclonal activators such as PHA, the addition of allogeneic MSC monolayer strongly inhibited CB lymphocytes proliferation.

The CB lymphocytes showed a strong proliferation response (mean incorporation of $5721.33 \pm 654.91 \mathrm{cpm}$ in MLR; 29428.67 $\pm 7928.87 \mathrm{cpm}$ in LTT). This could be suppressed in a dose-dependent way by the addition of increasing numbers of placental MSC to the cultures, resulting in a significantly lower response when $1 \times 10^{5} \mathrm{MSC}$ were added to the culture system (mean incorporation of $906.00 \pm 493.25 \mathrm{cpm}$ in MLR; $3611.33 \pm 919.03 \mathrm{cpm}$ in LTT, $p<0.01)$ and a lower response when MPC was 1. $25 \times 10^{4}$ (mean incorporation of $2595.34 \pm 176.98 \mathrm{cpm}$ in MLR; $14220.03 \pm 1519.88 \mathrm{cpm}$ in LTT, $p<0.01$ ), as shown in Fig. 6 and Fig. 7.

\section{DISCUSSION}

In this report, we describe the isolation and characterization of MSC from human placenta and demonstrate that these cells exhibited the capacity to modulate the UCB lymphocytes proliferation by allogeneic and nonspecific stimuli.

MSC have the capability for self-renewal and differentiation into various lineages of mesenchymal tissues. These features of MSC attract much attention from investigators with regard to tissue engineering and cell-based therapies. Despite the fact that BM represents the main available source of MSC, the use of BM derived cells is not always acceptable because of the significant decrease in cell number and proliferation/differentiation capacity with age. In this connection, most attention should be paid to tissues containing cells with higher proliferative potency, capability of differentiation, and low risk of contamination.
Placenta is likely a feasible source of MSC for two reasons. First, human placenta, as a castoff, can be obtained easily. Second, during ontogeny, the placenta, which contains a great deal of mesenchyma, is formed from extraembryonic mesoderm. Thus, MSC can be found in placenta.

We have proposed that pluripotent MSC derived from extraembryonic mesoderm, but not recruited to differentiate, may reside in a quiescent state within the placenta throughout gestation. We sought to determine whether recovery and cultivation of the placenta provided an opportunity to recruit and isolate MSC, which would possibly open a new and rich source of MSC for experimental and clinical needs. Our results confirmed this assumption. In this study, we were successfully isolate and identify human placental MSC. After density gradient centrifugation, when cultured placental MNC in medium for MSC, adherent cells were generated. In all of the 24 placental samples, various numbers of colonies were harvested. But the nature of the colonies was not same in all cases, not all the colonies could

\section{A}

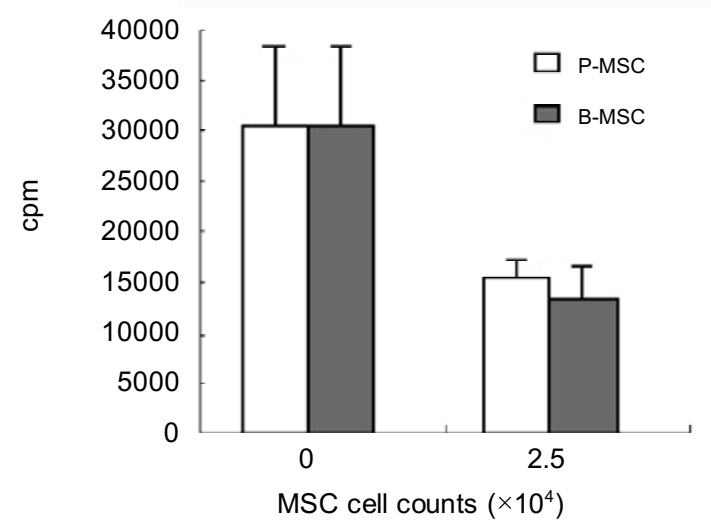

B

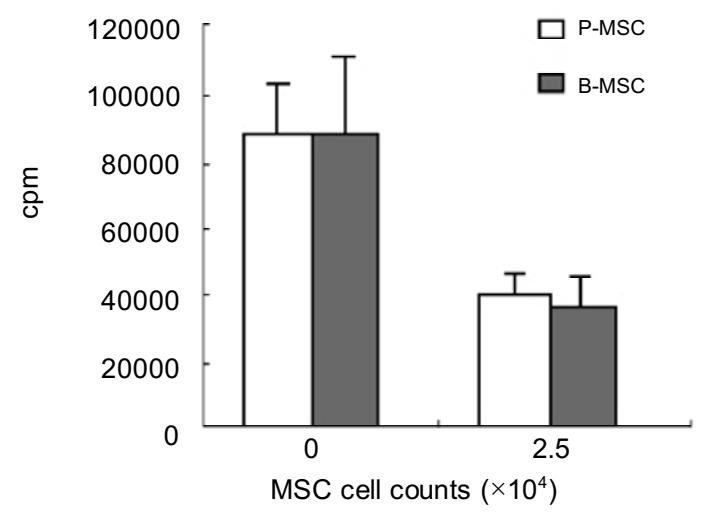

Fig. 5 MSC from human placenta suppressed PB lymphocytes proliferation like BM MSC. Responding PB lymphocytes $\left(2 \times 10^{5}\right.$ / well) were stimulated by allogeneic PB lymphocytes (A) or PHA (B). Irradiated MSC from placenta or from BM $\left(2.5 \times 10^{4} /\right.$ well $)$ were added to the cultures. 


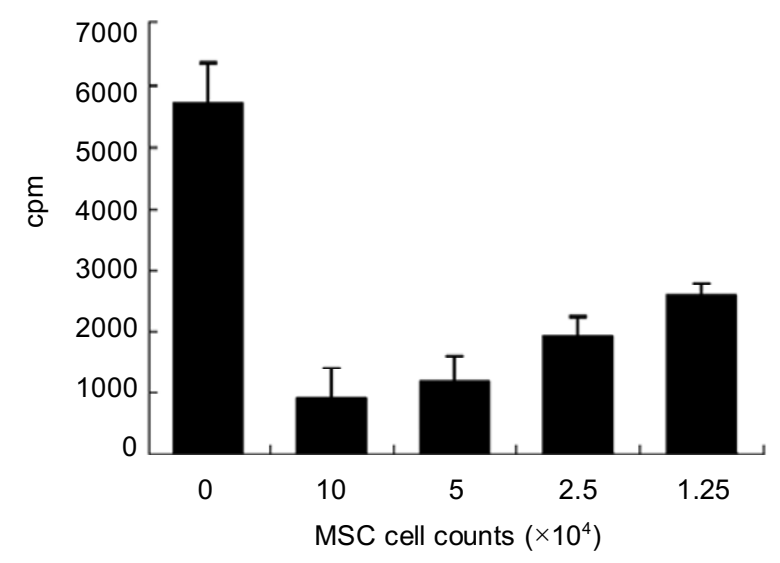

Fig. 6 MSC from human placenta decrease MLR of CB lymphocytes. Responding CB lymphocytes $\left(2 \times 10^{5} /\right.$ well) were incubated with a similar number of irradiated PB lymphocytes as stimulators. Variable numbers of irradiated MSC from placenta were added to the cultures. Bars show: MLR without MSC, MLR with $1 \times 10^{5}$ MSC, MLR with $5 \times 10^{4} \mathrm{MSC}$, MLR with $2.5 \times 10^{4} \mathrm{MSC}$, MLR with 1 . $25 \times 10^{4} \mathrm{MSC} /$ well, respectively.

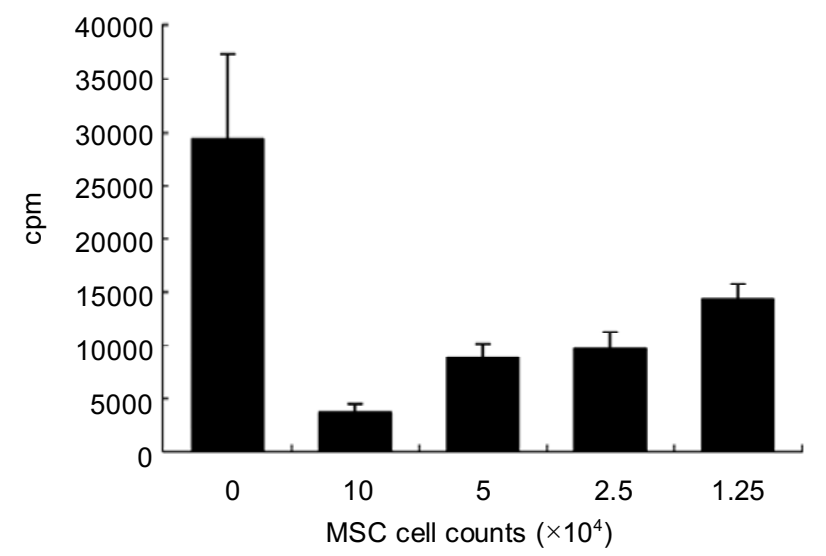

Fig. 7 MSC from human placenta decrease LTT of CB lymphocytes. Responding CB lymphocytes $\left(2 \times 10^{5} /\right.$ well) were incubated with nonspecific polyclonal activator, PHA $(2 \mu \mathrm{g} / \mathrm{ml})$, as stimulators. Variable numbers of irradiated MSC from placenta were added to the cultures. Bars show: LTT without MSC, LTT with $1 \times 10^{5} \mathrm{MSC}$, LTT with $5 \times 10^{4} \mathrm{MSC}$, LTT with $2.5 \times 10^{4} \mathrm{MSC}$, LTT with $1.25 \times 10^{4}$ $\mathrm{MSC} /$ well, respectively.

form an adherent layer and remain as fibroblast-like cells. The average number of the colonies which could be readily expanded in vitro by successive cycles of trypsin ization, seeding, and culture every $3 \mathrm{~d}$ for 15 passages without visible morphologic alteration and have immunop henotypic characterization of MSC in one placenta was $8.13 \pm 2.88$, while the total harvested colonies in one placenta was 25 .
17 \pm 6.76 . Six randomly selected colonies in different placentas were used for later experiments. Lines of evidence indicated that placental MSC we had identified were similar to those present in adult BM. First, their morphological and immunophenotype were similar to those of adult BM MSC, and they were clearly nonhematopoietic markers consistently CD $34^{-}, \mathrm{CD}_{4} 5^{-}$, as reported for adult $\mathrm{BM} \mathrm{MSC}$. Like BM MSC, placental MSC also expressed a large number of adhesion molecules, including CD29, CD44 and CD166, specific mesenchymal markers, such as CD105 (SH-2) [24] and CD73 (SH-3,4) [23], and HLA-ABC positive while HLA-DR negative. Second, human placental MSC had the similar cell cycle and growth characterization with BM-derived MSC, most of the cells were at quiescent phase and could self-renew rapidly. Finally and most important, like adult BMMSC, placental MSC had the ability to differentiate into different tissues. All of the 6 colonies derived cells showed signs of differentiation into osteocytes, adipocytes and chondrocyte when incubated in the induce media for $2-4 \mathrm{w}$, even after 10 passage in culture.

The data presented here demonstrate that a population of MSC was isolated from placenta of full-term pregnancy similar to those of adult BM derived MSC [25].These cells were not isolated from UCB of the same donor, thus emphasizing that placental MSC did not originate from the circulation.

Beyond that, we assessed the immunomodulatory capacity of placental MSC, which is important for clinic application. Animal models and in vitro studies showed that MSC is not substantially immunogenic and may actually inhibit both primary and secondary (MLR). Ongoing MLR may be suppressed by adding the responder, stimulator, or intriguingly, third-party MSC [15-17, 26, 27], correlating well with the peculiar immunophenotypic features of MSC, such as the lack of HLA class II and Tcell costimulatory molecule B7 $[28,29]$. Furthermore, an ongoing clinical trial has provided further exciting insight into the function of MSC. Lazarus et al. [30] reported a phase I study of MSC dose escalation that evaluated the cotransplantation of HLA-identical MSC together with either PB- or BM- derived HSC from the same donor in patients with advanced hematologic malignancies. The patients who received coinfusion of allo-MSC along with allo-BM were observed to have no significant toxicities and experienced a reduction of acute and chronic GVHD. Our result demonstrated that (1) culture-expanded placental MSC had an inhibitory effect on CB lymphocytes proliferation triggered by allogeneic $\mathrm{PB}$ lymphocytes or PHA; and (2) this effect was dose dependent. Although preliminary, this observation provides additional evidence on the potential immunomodulatory properties of human placental 
MSC, which may play a major role in the induction of tolerance to allogeneic, especially UCB transplantation. The mechanism underlying placental MSC mediated suppression of T-cell proliferation requires further investigation using appropriate in vivo models. Soluble factors such as TGF- $\beta$ and hepatic growth factor may play a role in this regulatory effect.

In conclusion, isolation of MSC from human placenta is promising not only in terms of origin but also as a novel microenvironment system with hematopoietic supportive and immunoregulatory features for UCB transplantation.

\section{ACKNOWLEDGEMENTS}

This study was supported by a grant from National Natural Science Foundation of China (No.30271245), HiTech Research and Development Program of China (863 Program) (No. 2003AA205170), National Basic Research Program of China (973 Program) (No.G1999054302), and a grant from Beijing Gynecology and Obstetrics Hospital Affiliate of Capital University of Medical Sciences.

Received, Feb 24, 2005

Revised, June 10, 2005

Accepted, June 21, 2005

\section{REFERENCES}

1 Friedenstein AJ, Gorskaja JF, Kulagina NN. Fibroblast precursors in normal and irradiated mouse hematopoietic organs. Exp Hematol 1976; 4:267-74.

2 Caplan A. Mesenchymal stem cells. J Ortho Res 1991; 9:64150.

3 Williams JT, Southerland SS, Souza J, et al. Cells isolated from adult human skeletal muscle capable of differentiating into multiple mesodermal phenotypes. Am Surg 1999; 65:22-6.

4 Warejcka DJ, Harvey R, Taylor BJ, et al. A population of cells isolated from rat heart capable of differentiating into several mesodermal phenotypes. J Surg Res 1996; 62:233-42.

5 Gronthos S, Zannettino AC, Graves SE, et al. Differential cell surface expression of the STROP-1 and alkaline phosphatase antigens on discrete development stages in primary cultures of human bone cells. J Bone Miner Res 1999; 14:47-56.

6 Grigoriadis AE, Heersche JN, Aubin JE. Differentiation of muscle, fat, cartilage, and bone from progenitor cells present in a bone derived clonal cell population: effect of dexamethason. J Cell Biol 1998; 106:2139-51.

7 Loncar D. Ultrastructural analysis of differentiation of rat endoderm in vitro: Adipose vascular-stromal cells induce endoderm differentiation, which in turn induces differentiation of vascularstromal cells into chondrocytes. J Submicrose Cytol Pathol 1992; 24:509-19.

8 Romanov YA, Svintsitskaya VA, Smirnov VN. Searching for alternative sources of postnatal human mesenchymal stem cells: candidate MSC-Like cells from umbilical cord. Stem cells 2003; 21:105-10.

9 Campagnoli C, Roberts IA, Kumar S, et al. Identification of mesenchymal stem/progenitor cells in human first-trimester fetal blood, liver, and bone marrow. Blood 2001; 98:2396-402.

10 Erices A, Conget P, Minguell JJ. Mesenchymal progenitor cells in human umbilical cord blood. Br J Haematol 2000; 109:235-42.

11 Mareschi K, Biasin E, Piacibello W, et al. Isolation of human mesenchymal stem cells: bone marrow versus umbilical cord blood. Haematologica 2001; 86:1099-100.

12 Pittinger M, Mackay A, Beck S, et al. Multilineage potential of adult human mesenchymal stem cells. Science 1999; 284:1437.

13 Haynesworth SE, Baber MA, Caplan AI. Cytokine expression by human marrow-derived mesenchymal progenitor cells in vitro: effects of dexamethasone and IL-1alpha. J Cell Physiol 1996; 166:585-92.

14 Majumdar MK, Thiede MA, Mosca JD, et al. Phenotypic and functional comparison of cultures of marrow-derived mesenchymal stem cells (MSC) and stromal cells. J Cell Physiol 1998; 176:57-66

15 Blanc KL, Tammik C, Rosendahl K, et al. HLA expression and immunologic properties of differentiated and undifferentiated mesenchymal stem cells. Exp Hematol 2003; 31:890-6.

16 Le Blanc K. Immunomodulatory effects of fetal and adult mesenchymal stem cells. Cytotherapy 2003; 5:485-9.

17 Bartholomew A, Sturgeon C, Siatskas M, et al. Mesenchymal stem cells suppress lympgocyte proliferation in vitro and prolong skin graft survival in vivo. Exp Hematol 2002; 30:42-8.

18 Di Nicola M, Carlo-Stella C, Magni M, et al. Human bone marrow stromal cells suppress T-lymphocyte proliferation induced by cellular or nonspecific mitogenic stimuli. Blood 2002; 99: 3838-43.

19 He J, Zhang Y, Jiang XX, et al. Isolation and characterization of human placenta derived adherent cells and their hematopoietic growth factor expression, Zhonghua Xue Ye Xue Za Zhi 2003; 24:652-4.

20 Zhang Y, Li CD, Jiang X, et al. Human placenta-derived mesenchymal progenitor cells support culture expansion of long-term culture-initiating cells from cord blood $\mathrm{CD} 34^{+}$cells. Exp Hematol. 2004; 32:657-64.

21 Bruder SP, Jaiswal N, Haynesworth SE. Growth kinetics, selfrenewal, and the osteogenic potential of purified human mesenchymal stem cells during extensive subcultivation and following cryopreservation. J Cell biochem 1997; 64:278-94.

22 Conget PA, Minguell JJ. Phenotypical and functional properties of human bone marrow mesenchymal progenitor cells. J Cell Physiol 1999; 181:67-73.

23 Barry F, Boynton R, Murphy M, et al. The SH-3 and SH-4 antibodies recognize distinct epitopes on CD73 from human mesenchymal stem cells. Biochem Biophys Res Commun 2001 30; 289:519-24.

24 Barry FP, Boynton RE, Haynesworth S, et al. The monoclonal antibody SH-2, raised against human mesenchymal stem cells, recognizes an epitope on endoglin (CD105). Biochem Biophys Res Commun 1999; 265:134-9.

25 Zhang Y, Li CD, Jiang XX, et al. Comparison of mesenchymal stem cells from human placenta and bone marrow. Chin Med J (Engl). 2004; 117:882-7.

26 Sun SK, Guo ZK, Xiao XR, et al. Isolation of mouse marrow mesenhymal progenitors by a novel and reliable method. Stem Cells. 2003; $21: 527-35$. 
27 Krampera M, Glennie S, Dyson J, et al. Bone marrow mesenchymal stem cells inhibit the response of naive and memory antigen-specific $\mathrm{T}$ cells to their cognate peptide. Blood 2003; 101:3722-9. Epub 2002 Dec 27.

28 Maccario R, Podesta M, Moretta A, et al. Interaction of human mesenchymal stem cells with cells involved in alloantigen-specific immune response favors the differentiation of $\mathrm{CD} 4^{+} \mathrm{T}$-cell subsets expressing a regulatory/suppressive phenotype. Haema tologica 2005; 90:516-25.
29 Lazarus HM, Haynesworth SE, Gerson SL, et al. Ex vivo expansion and subsequent infusion of human bone marrowderived stromal progenitor cells (mesenchymal progenitor cells): implications for therapeutic use. Bone Marrow Transplant 1995; 16: 557-64.

30 Chung NG, Jeong DC, Park SJ, et al. Cotransplantation of marrow stromal cells may prevent lethal graft-versus-host disease in major histocompatibility complex mismatched murine hematopoietic stem cell transplantation. Int J Hematol 2004; 80:370-6. 